\title{
AN INTERESTING APPLICATION OF SIMPLE EXPONENTIAL SMOOTHING IN MUSIC ANALYSIS
}

\author{
Soubhik Chakraborty ${ }^{1 *}$, Saurabh Sarkar $^{2}$, Swarima Tewari $^{3}$ and Mita Pal ${ }^{4}$ \\ 1, 2, 3, 4 Department of Applied Mathematics, Birla Institute of Technology Mesra, Ranchi- \\ 835215 , India \\ soubhikc@yahoo.co.in, saurabh.4002@gmail.com, swarimatewari@gmail.com, \\ mitapal_25@rediffmail.com \\ *email address of the corresponding author: soubhikclyahoo.co.in
}

(S. Chakraborty)

\begin{abstract}
Modeling a musical structure or performance is a coveted research area in scientific analysis of music. We are motivated to analyze the structure of raga Bhairavi through a simple exponential model in this paper. Analyzing a raga structure helps in giving an approximate model that captures the raga note progression in general without brining the style of a particular artist into play. The style is, however, important in performance analysis where we get additional features like note duration and pitch movements between the notes.
\end{abstract}

\section{KEY WORDS}

Simple exponential modeling, raga, melody, structure, time series

\section{INTRODUCTION}

Exponential smoothing is used to statistically model time series data for smoothing purpose or for prediction. Although it was (Holt 1957) who proposed it first, it is Brown's simple exponential smoothing that is commonly used nowadays (Brown 1963).

In its simplest form, exponential smoothing is given by the formulae:

$$
\begin{aligned}
& s_{1}=x_{0} \\
& s_{t}=\alpha x_{t-1}+(1-\alpha) s_{t-1}=s_{t-1}+\alpha\left(x_{t-1}-s_{t-1}\right), t>1
\end{aligned}
$$

where $\alpha$ is the smoothing factor, and $0<\alpha<1$. In other words, the smoothed statistic $s_{t}$ is a simple weighted average of the previous observation $x_{t-1}$ and the previous smoothed statistic $s_{t-1}$. The term smoothing factor applied to $\alpha$ here is something of a misnomer, as larger values of $\alpha$ actually reduce the level of smoothing, and in the limiting case with $\alpha=1$ the output series is just 
the same as the original series (with lag of one time unit). Simple exponential smoothing is easily applied, and it produces a smoothed statistic as soon as two observations are available.

\section{Why is it "exponential"?}

By direct substitution of the defining equation for simple exponential smoothing back into itself we find that

$$
\begin{aligned}
s_{t} & =\alpha x_{t-1}+(1-\alpha) s_{t-1} \\
& =\alpha x_{t-1}+\alpha(1-\alpha) x_{t-2}+(1-\alpha)^{2} s_{t-2} \\
& =\alpha\left[x_{t-1}+(1-\alpha) x_{t-2}+(1-\alpha)^{2} x_{t-3}+(1-\alpha)^{3} x_{t-4}+\cdots\right]+(1-\alpha)^{t-1} x_{0} .
\end{aligned}
$$

In other words, as time passes the smoothed statistic $s_{t}$ becomes the weighted average of a greater and greater number of the past observations $x_{t-n}$, and the weights assigned to previous observations are in general proportional to the terms of the geometric progression $\left\{1,(1-\alpha),(1-\alpha)^{2},(1-\alpha)^{3}, \ldots\right\}$. A geometric progression is the discrete version of an exponential function, so this is where the name for this smoothing method originated.

Remark: Some authors call it Single Exponential Smoothing to distinguish it from Double Exponential Smoothing.

Values of $\alpha$ close to one have less of a smoothing effect and give greater weight to recent changes in the data, while values of $\alpha$ closer to zero have a greater smoothing effect and are less responsive to recent changes. There is no formally correct procedure for choosing $\alpha$. Sometimes the statistician's judgment is used to choose an appropriate factor. Alternatively, a statistical technique may be used to optimize the value of $\alpha$. For example, the method of least squares might be used to determine the value of $\alpha$ for which the sum of the quantities $\left(s_{n-1}-x_{n-1}\right)^{2}$ is minimized. (see http://en.wikipedia.org/wiki/Exponential_smoothing for further literature).

Musical data is certainly chronological and the numbers representing pitches in different octaves (detailed in table 1) will be the possible response entry $\mathbf{x}_{\mathrm{t}}$ corresponding to the argument time $\mathbf{t}$ which would in our case(i.e. structure analysis) be just the instance $(1,2,3 \ldots)$ at which a musical note is realized. With modeling a musical structure or performance being a coveted research area in scientific analysis of music, we are motivated to analyze the structure of raga Bhairavi through a simple exponential model in this paper. A raga is the nucleus of Indian classical music-both Hindustani and Carnatic-and may be defined as a melodic structure comprising of fixed notes and a set of rules characterizing a certain musical emotion conveyed by performance (Chakraborty et al. 2009). Analyzing a raga structure helps in giving an approximate model that captures the raga note progression in general without brining the style of a particular artist into play. On the other hand, performance analysis gives additional features like note duration and the pitch movements between notes etc. Readers interested in performance analysis are referred to (Tewari and Chakraborty 2011). We are motivated by the works of (Adiloglu, Noll and Obermayer 2006).Our database for analysis comprises of a sequence of notes of raga Bhairavi taken from standard text (Dutta 2006).This is given in table 2. 
International Journal on Soft Computing, Artificial Intelligence and Applications (IJSCAI), Vol.2, No.4, August 2013

Table 1: Numbers representing pitches in three octaves

\begin{tabular}{|c|c|c|c|c|c|c|c|c|c|c|c|c|}
\hline $\mathrm{C}$ & $\mathrm{Db}$ & $\mathrm{D}$ & $\mathrm{Eb}$ & $\mathrm{E}$ & $\mathrm{F}$ & $\mathrm{F} \#$ & $\mathrm{G}$ & $\mathrm{Ab}$ & $\mathrm{A}$ & $\mathrm{Bb}$ & $\mathrm{B}$ & \\
\hline $\mathrm{S}$ & $\mathrm{r}$ & $\mathrm{R}$ & $\mathrm{g}$ & $\mathrm{G}$ & $\mathrm{M}$ & $\mathrm{m}$ & $\mathrm{P}$ & $\mathrm{d}$ & $\mathrm{D}$ & $\mathrm{n}$ & $\mathrm{N}$ & (lower octave) \\
\hline-12 & -11 & -10 & -9 & -8 & -7 & -6 & -5 & -4 & -3 & -2 & -1 & \\
\hline $\mathrm{S}$ & $\mathrm{r}$ & $\mathrm{R}$ & $\mathrm{g}$ & $\mathrm{G}$ & $\mathrm{M}$ & $\mathrm{m}$ & $\mathrm{P}$ & $\mathrm{d}$ & $\mathrm{D}$ & $\mathrm{n}$ & $\mathrm{N}$ & (middle octave) \\
\hline 0 & 1 & 2 & 3 & 4 & 5 & 6 & 7 & 8 & 9 & 10 & 11 & \\
\hline $\mathrm{S}$ & $\mathrm{r}$ & $\mathrm{R}$ & $\mathrm{g}$ & $\mathrm{G}$ & $\mathrm{M}$ & $\mathrm{m}$ & $\mathrm{P}$ & $\mathrm{d}$ & $\mathrm{D}$ & $\mathrm{n}$ & $\mathrm{N}$ & (higher octave) \\
\hline 12 & 13 & 14 & 15 & 16 & 17 & 18 & 19 & 20 & 21 & 22 & 23 & \\
\hline
\end{tabular}

Abbreviations: The letters S, R, G, M, P, D and N stand for Sa, Sudh Re, Sudh Ga, Sudh $\mathrm{Ma}, \mathrm{Pa}$, Sudh Dha and Sudh Ni respectively. The letters r, g, m, d, n represent Komal Re, Komal Ga, Tibra Ma, Komal Dha and Komal Ni respectively. Normal type indicates the note belongs to middle octave; italics implies that the note belongs to the octave just lower than the middle octave while a bold type indicates it belongs to the octave just higher than the middle octave. Sa, the tonic in Indian music, is taken at C. Corresponding Western notation is also provided. The terms "Sudh", "Komal" and "Tibra" imply, respectively, natural, flat and sharp. 
International Journal on Soft Computing, Artificial Intelligence and Applications (IJSCAI), Vol.2, No.4, August 2013

Table 2 Note Sequence of raga Bhairavi (refer to table 1 to identify the note and its octave)

\begin{tabular}{|c|c|c|c|c|c|c|c|c|c|c|c|c|c|}
\hline Slne, & Pitch & Slne & Pitch & Slno, & Pitch & Slne, & Pitch & Slne, & Pitch & Slno, & Pitch & Slne & Pitch \\
\hline 1 & -2 & 41 & 1 & 81 & 3 & 121 & 1 & 161 & 12 & 201 & 10 & 241 & 7 \\
\hline 2 & 0 & 42 & 3 & 82 & 5 & 122 & 0 & 162 & 15 & 202 & 12 & 242 & 8 \\
\hline 3 & 3 & 43 & 5 & 83 & 7 & 123 & 0 & 163 & 13 & 203 & 15 & 243 & 7 \\
\hline 4 & 1 & 44 & 3 & 84 & 3 & 124 & 1 & 164 & 12 & 204 & 13 & 244 & 5 \\
\hline 5 & 0 & 45 & 1 & 85 & 5 & 125 & 3 & 165 & 17 & 205 & 12 & 245 & 7 \\
\hline 6 & -4 & 46 & 0 & 86 & 7 & 126 & 5 & 166 & 15 & 206 & 10 & 246 & 5 \\
\hline 7 & -2 & 47 & -4 & 87 & 8 & 127 & 3 & 167 & 13 & 207 & 8 & 247 & 3 \\
\hline 8 & 0 & 48 & -2 & 88 & 7 & 128 & 1 & 168 & 12 & 208 & 7 & 248 & 1 \\
\hline 9 & 0 & 49 & 0 & 89 & 10 & 129 & 0 & 169 & 10 & 209 & 8 & 249 & 0 \\
\hline 10 & 3 & 50 & -2 & 90 & 8 & 130 & -4 & 170 & 12 & 210 & 7 & - & - \\
\hline 11 & 5 & 51 & 0 & 91 & 7 & 131 & -2 & 171 & 8 & 211 & 7 & - & - \\
\hline 12 & 7 & 52 & 3 & 92 & 3 & 132 & 0 & 172 & 10 & 212 & 10 & - & - \\
\hline 13 & 3 & 53 & 5 & 93 & 5 & 133 & 1 & 173 & 7 & 213 & 8 & - & - \\
\hline 14 & 5 & 54 & 7 & 94 & 7 & 134 & 3 & 174 & 8 & 214 & 7 & - & - \\
\hline 15 & 3 & 55 & 8 & 95 & 10 & 135 & 5 & 175 & 5 & 215 & 5 & - & - \\
\hline 16 & 1 & 56 & 5 & 96 & 8 & 136 & 7 & 176 & 7 & 216 & 5 & - & - \\
\hline 17 & 3 & 57 & 7 & 97 & 12 & 137 & 8 & 177 & 5 & 217 & 3 & - & - \\
\hline 18 & -4 & 58 & 5 & 98 & 10 & 138 & 5 & 178 & 3 & 218 & 1 & - & - \\
\hline 19 & -2 & 59 & 3 & 99 & 12 & 139 & 7 & 179 & 1 & 219 & 0 & - & - \\
\hline 20 & 0 & 60 & 5 & 100 & 10 & 140 & 3 & 180 & 0 & 220 & 10 & - & - \\
\hline 21 & 1 & 61 & 3 & 101 & 8 & 141 & 5 & 181 & 0 & 221 & 0 & - & - \\
\hline 22 & 3 & 62 & 1 & 102 & 12 & 142 & 7 & 182 & 3 & 222 & 3 & - & - \\
\hline 23 & 1 & 63 & 0 & 103 & 10 & 143 & 8 & 183 & 1 & 223 & 5 & - & - \\
\hline 24 & 0 & 64 & -2 & 104 & 12 & 144 & 10 & 184 & 0 & 224 & 7 & - & - \\
\hline 25 & 0 & 65 & 0 & 105 & 13 & 145 & 8 & 185 & 1 & 225 & 7 & - & - \\
\hline 26 & 1 & 66 & 7 & 106 & 12 & 146 & 10 & 186 & 3 & 226 & 8 & - & - \\
\hline 27 & 0 & 67 & 7 & 107 & 10 & 147 & 12 & 187 & 5 & 227 & 10 & - & - \\
\hline 28 & -4 & 68 & 7 & 108 & 12 & 148 & -11 & 188 & 8 & 228 & 7 & - & - \\
\hline 29 & -2 & 69 & 8 & 109 & 10 & 149 & 12 & 189 & 7 & 229 & 8 & - & - \\
\hline 30 & 0 & 70 & 10 & 110 & 8 & 150 & 15 & 190 & 8 & 230 & 5 & - & - \\
\hline 31 & 5 & 71 & 7 & 111 & 7 & 151 & -11 & 191 & 10 & 231 & 7 & - & - \\
\hline 32 & 3 & 72 & 8 & 112 & 8 & 152 & 12 & 192 & 12 & 232 & 3 & - & - \\
\hline 33 & 1 & 73 & 5 & 113 & 10 & 153 & 10 & 193 & 10 & 233 & 5 & - & - \\
\hline 34 & 0 & 74 & 7 & 114 & 8 & 154 & 12 & 194 & 12 & 234 & 3 & - & - \\
\hline 35 & -4 & 75 & 5 & 115 & 5 & 155 & 8 & 195 & 15 & 235 & 1 & - & - \\
\hline 36 & -2 & 76 & 3 & 116 & 7 & 156 & 7 & 196 & 17 & 236 & 0 & - & - \\
\hline 37 & 0 & 77 & 1 & 117 & 5 & 157 & 8 & 197 & 15 & 237 & -2 & - & - \\
\hline 38 & -4 & 78 & 0 & 118 & 3 & 158 & 5 & 198 & 13 & 238 & 0 & - & - \\
\hline 39 & -2 & 79 & -2 & 119 & 5 & 159 & 8 & 199 & 12 & 239 & 3 & - & - \\
\hline 40 & 0 & 80 & 0 & 120 & 3 & 160 & 10 & 200 & 8 & 240 & 5 & - & - \\
\hline
\end{tabular}

\section{Simple (Single) EXPONENTIAL SMOOTHING}

Simple (Single) exponential Smoothing is achieved with the help of MINITAB statistical package version 15 . The results are given in fig. 1 below.

* NOTE * Zero values of Xt exist; MAPE calculated only for non-zero Xt. 


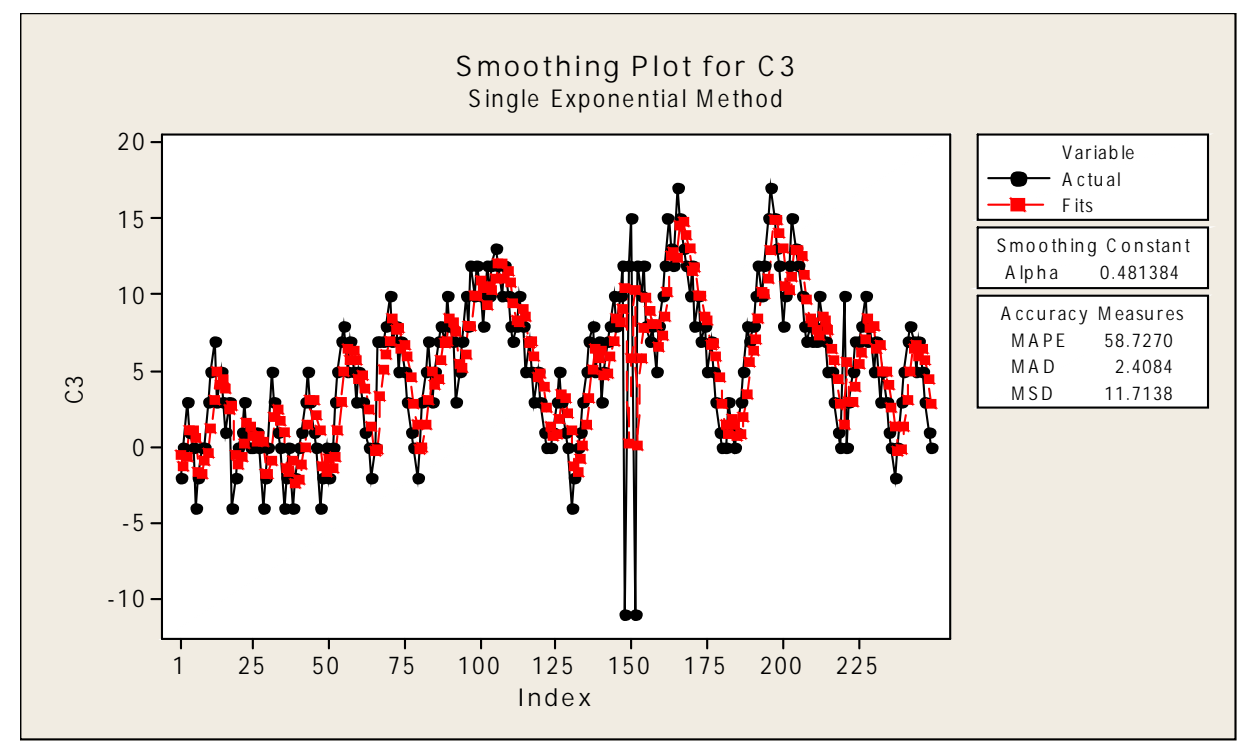

Fig. 1 Observed versus predicted values of $\mathrm{x}_{\mathrm{t}}$ for Simple Exponential Smoothing (alpha $\left.=0.481384\right)$

\section{RAGA IDENTIFICATION AND MELODY SIGNIFICANCE}

The fact that the note sequence corresponds to raga Bhairavi can be easily identified through the aroh-awaroh (ascent-decent) pattern that is followed throughout the sequence in table 2 (this can be verified by a suitable string matching algorithm; we omit the details) and through some note combinations as are typical of the raga such as $\{n \mathrm{~S} g \mathrm{M} \mathrm{P} \mathrm{dP}\}$ or in our notation $\{-2,0,3,5,7$, $8,7\}$. The aroh-awaroh of this raga and other fundamental features are as follows:-

\section{Musical Features of raga Bhairavi (Dutta, 2006)}

Thaat (raga group according to scale): Bhairavi

\section{Aroh (ascent): S r g M P d n S Awaroh (descent): S n d P M g r S}

Jati: Sampoorna-Sampoorna (seven distinct notes allowed in both ascent and descent)

Vadi swar (most important note): M (some say d)

Samvadi swar (second most important note): S (some say r)

Anga: Uttaranga Pradhan (second half more important) Pakad (catch): M g S r S d n S

Nyas swar (stay notes): g, M, P Suitable time of rendition: 6AM to 9AM

Remark: The well known musicologist late Suresh Chandra Chakraborty has traced the origin of Bhairavi to the music of Bhirba, an ancient tribe in Bengal (Chakraborty 1965). He also mentions that Lochan Pandit in his book Ragatarangini has stated an interesting fact: if one renders the notes of raga Kafi one after another first in ascending order $\{\mathrm{S} \mathrm{R} \mathrm{g} \mathrm{M} \mathrm{P} \mathrm{D} \mathrm{n} \mathbf{S}\}$ and then in 
descending order (S n D P M g R S \}, it creates an atmosphere of Bhairavi! Possibly the use of komal dha (d) in Bhairavi started during the times of Lochan Pandit.

Defining melody as a sequence of musical notes that is complete (if incomplete, it is called a segment) we measure its significance by multiplying its length, which gives the number of notes in it, by the number of times it occurs in the entire sequence. Our analysis yields table 3. Melody group $\left\{\begin{array}{llllllllllll}-4 & -2 & 0 & 1 & 3 & 5 & 3 & 1 & 0 & -4 & -2 & 0\end{array}\right\}$ which comes once only with significance measure 12 and the six note melody $\{5,3,5,3,1,0\}$ which comes twice with significance $6 \times 2=12$ are the most significant.

Table 3 Melody groups which give a sequence of notes that can be taken as complete

\begin{tabular}{|c|c|}
\hline Group No. & 20 \\
\hline 1 & $-203100-4-20$ \\
\hline 2 & 0357 \\
\hline 3 & 353310 \\
\hline 4 & $4-4 \quad-20013310$ \\
\hline 5 & $010-4-20$ \\
\hline 6 & $53100-4-20$ \\
\hline 7 & $-4-201135531004-40$ \\
\hline 8 & $\left\{\begin{array}{llllll}-2 & 0 & 3 & 5 & 7\end{array}\right\} 8557$ \\
\hline 9 & $\left\{\begin{array}{llllll}5 & 3 & 5 & 3 & 1 & 0\end{array}\right.$ \\
\hline 10 & -207228107857 \\
\hline 11 & $\left\{\begin{array}{lllllll}5 & 3 & 1 & 0\end{array}\right\}$ \\
\hline 12 & $\left\{\begin{array}{lllll}-2 & 0 & 3 & 5 & 7\end{array}\right\}$ \\
\hline 13 & 35787 \\
\hline 14 & 1087357 \\
\hline 15 & $\{8 \quad 108 \quad 1012\}$ \\
\hline 16 & $108 \quad 12 \quad 10 \quad 12 \quad 13 \quad 12$ \\
\hline 17 & 10121087 \\
\hline 18 & 810857 \\
\hline 19 & $\left\{\begin{array}{llllll}5 & 3 & 5 & 3 & 1 & 0\end{array}\right.$ \\
\hline 20 & 0135310 \\
\hline 21 & $4-201357$ \\
\hline 22 & $\left\{\begin{array}{lllllll}8 & 5 & 7 & 3 & 5\end{array}\right\}$ \\
\hline 23 & $\{81081012\}$ \\
\hline 24 & $\begin{array}{lllllllll}-11 & 12 & 15 & -11 & 12 & 10 & 12\end{array}$ \\
\hline 25 & 878581012 \\
\hline 26 & $\begin{array}{lllllll}5 & 13 & 12 & 17 & 15 & 13 & 12\end{array}$ \\
\hline 27 & 10128107857 \\
\hline 28 & $\left\{\begin{array}{llll}5 & 3 & 1 & 0\end{array}\right.$ \\
\hline 29 & 0310 \\
\hline 30 & 13587 \\
\hline 31 & 810121012 \\
\hline 32 & $\begin{array}{lllll}15 & 17 & 15 & 13 & 12\end{array}$ \\
\hline 33 & $\begin{array}{llllllll}8 & 10 & 12 & 15 & 13 & 12\end{array}$ \\
\hline 34 & 8787 \\
\hline 35 & 710875 \\
\hline 36 & 5310100 \\
\hline 37 & 35778107 \\
\hline 38 & $\{85773 \quad 5\} 310$ \\
\hline 39 & $\left\{\begin{array}{lllll}-2 & 0 & 3 & 5 & 7\end{array}\right\} 87$ \\
\hline 40 & 575310 \\
\hline
\end{tabular}

Note: Middle bracketed \{ \} content corresponds to similar sequence of notes found elsewhere in the series

\section{Conclusion}

We have successfully captured the Bhairavi structure, as depicted by a long note sequence, by a Simple Exponential model with smoothing factor 0.481384 . We have also identified the raga correctly through aroh-awaroh pattern and some typical note combinations. Melody analysis reveals the 12 note melody $\left\{\begin{array}{llllllllllll}-4 & -2 & 0 & 1 & 3 & 5 & 3 & 1 & 0 & -4 & -2 & 0\end{array}\right\}$ which comes once only and the six 
note melody $\{5,3,5,3,1,0\}$ which comes twice as the most significant with significance measure 12 each.

One advantage with simple exponential modeling is that the inner mechanism is fairly straightforward and as such can be easily understood by a general audience. For instance, in our case, the modeling can be appreciated even by the musical community. The present paper is primarily intended to create a platform for raising questions such as: Which are the ragas that can be characterized well by a simple exponential model? For such ragas, how does the smoothing factor vary when these ragas belong to the same thaat in comparison to those of different thaats? Is there any noteworthy change in the smoothing factor when a morning raga is compared with, say, a night raga? It is easy to convince the musical community how scientific research in music helps in understanding music better by raising and answering such questions. To answer these queries, we propose to experiment with a database of 50 ragas, five each from the ten thaats, so selected (from a much larger database of say 500 ragas) such that the simple exponential modeling holds in each of the 50 ragas. Additionally, experimenting with more sophisticated smoothing techniques like Kalman filter where the smoothing factor dynamically changes is also reserved as a rewarding future work.

\section{ACKNOWLEDGEMENT}

This research is a part of a UGC Major Research Project. We thank the University Grants Commission (UGC) for the sponsorship (Sanction Letter No.F.N.5-412/2010 (HRP); draft no. 392889 dated 28.02.2011). We also thank an anonymous referee for helping us bring this paper to its final form.

\section{REFERENCES}

[1] Adiloglu K, Noll T, Obermayer K (2006) A Paradigmatic Approach to Extract the melodic Structure of a Musical Piece. Journal of New Music Research,Vol.35(3),p.221-236

[2] Brown, Robert Goodell (1963) Smoothing Forecasting and Prediction of Discrete Time Series. Engle wood Cliffs, NJ:Prentice-Hall

[3] Chakraborty SC (1965) Raga Rupayan, General Printers and Publishers Pvt. Ltd. Kolkata (Bengali)

[4] Chakraborty S, Ranganayakulu R, Chauhan S, Solanki SS, Mahto K (Winter 2009) A Statistical Analysis of Raga Ahir Bhairav.Journal of Music and Meaning,Vol.8,sec.4,http://www.musicandmeaning.net/issues/showArticle.php?artID=8.4

[5] Dutta D (2006) Sangeet Tattwa (Pratham Khanda), Brati Prakashani,5th ed,(Bengali)

[6] Holt, Charles C (1957) "Forecasting Trends and Seasonal by Exponentially Weighted Averages". Office of Naval Research Memorandum 52.reprinted in Holt,Charles C.(January-March 2004)."Forecasting Trends and Seasonal by Exponentially Weighted Averages". International Journal of Forecasting 20 (1):5-10.doi:10.1016/j.ijforecast.2003.09.015

[7] Tewari S, Chakraborty S (2011) A Statistical Analysis of Raga Bhairavi,Acoustic Waves.S.K.Srivastava,Kailash,K.Chaturvedi(Ed.),Shree Publishers and Distributors,New Delhi,p.329-336

[8] http://en.wikipedia.org/wiki/Exponential_smoothing 


\section{Biography of the authors}

Dr. Soubhik Chakraborty, a $\mathrm{PhD}$ in Statistics, is an associate professor in the department of Applied Mathematics, BIT Mesra, Ranchi, India. He has published several papers in algorithm and music analysis and is guiding research scholars in both the areas. $\mathrm{He}$ is a reviewer of prestigious journals like Mathematical Reviews (American Mathematical Society), Computing Reviews (ACM) and IEEE Transactions on

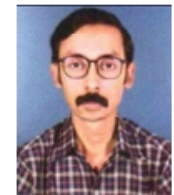
Computers etc. besides being the Principal Investigator of a UGC major rescarch project on music analysis in his department. $\mathrm{He}$ is also an amateur harmonium player.

Mr. Saurabh Sarkar, a B.E. in Applied Electronics \& Instrumentation Engg., is a Project Fellow of a UGC major research project on music analysis in the department of Applied Mathematics, BIT Mesra, Ranchi, India. He has published some papers in music analysis and is interested in pursuing a $\mathrm{PhD}$ in Soft Computing and Artificial lntelligence involving music analysis.

Mrs. Swarima Tewari, a B.E. in Electrical Enginecring and an M.'Tech in Scientific Computing, is presently doing her PhI) in the area of Computational Musicology from BI'T Mesra, Ranchi, India under the guidanee of the first author. She has published scveral papers in music analysis.

Mrs. Mita Pal, an MCA, is doing her PhI) in algorithm analysis from BI'T Mesra, Ranchi, India under the guidance of the first author. She has published several papers in algorithm analysis and a few in music analysis as well with this rescarch team.
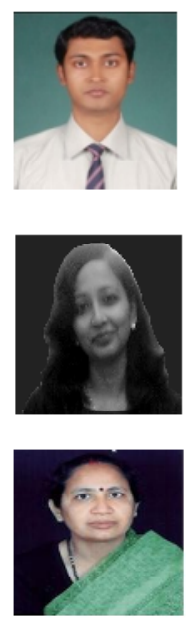